ORIGINAL ARTICLE

\title{
Effects of air pollution on changes in lung function induced by exercise in children with chronic respiratory symptoms
}

\author{
K L Timonen, J Pekkanen, P Tiittanen, R O Salonen
}

Occup Environ Med 2002;59:129-134

See end of article for authors' affiliations

Correspondence to:

Ms K Timonen, Department of Clinical Physiology and Nuclear Medicine, Kuopio

University Hospital, PO Box

1777, FIN 70211,

Kuopio, Finland;

Kirsi.Timonen@ktl.fi

Accepted 27 July 2001
Objective: To investigate how daily variations in ambient air pollution, especially in particles, during the cold of winter affect repeated measurements of baseline lung function and exercise induced bronchial responsiveness among primary school children with chronic respiratory symptoms.

Methods: During alternate school weeks (mamimum five) from February to April 1994, 33 children took part in exercise challenge tests ( $n=141$ tests). The exercise challenges were conducted outdoors in a school yard in the centre of Kuopio, Finland. Spirometric lung functions were measured indoors before the exercise, and 3 and 10 minutes after. Daily mean concentrations of $\mathrm{PM}_{10}$, black smoke (BS), $\mathrm{NO}_{2}, \mathrm{CO}, \mathrm{SO}_{2}$, and particle size and numbers were monitored at a nearby fixed monitoring site.

Results: Daily variations in ambient air pollution were not associated with enhanced bronchial responsiveness. However, increased concentrations of $\mathrm{BS}, \mathrm{PM}_{10}$, particle numbers, $\mathrm{NO}_{2}$, and $\mathrm{CO}$ were consistently associated with an impairment of baseline lung functions. The reductions in forced vital capacity (FVC) and forced expiratory volume in 1 second $\left(\mathrm{FEV}_{1}\right)$ were $0.5 \%$ and $0.6 \%$, respectively, for each $10 \mu \mathrm{g} / \mathrm{m}^{3}$ increase in BS (lag 2).

Conclusion: Particles derived from combustion affect baseline lung function rather than bronchial responsiveness among children with chronic respiratory symptoms.
$\mathrm{D}$ aily variations in ambient air particulate pollution have been shown to be associated with a broad range of adverse health effects among susceptible groups in the population. These effects have included decline in lung function in numerous studies. ${ }^{1-3}$ People with asthma, especially children, are regarded as one of the most sensitive groups in this respect. ${ }^{145}$

A characteristic feature of asthma is bronchial hyperresponsiveness to a wide range of exogenous stimuli such as histamine, methacholine, and cold or warm dry air. Airway narrowing after vigorous exercise is very common among children and adolescents with asthma. Therefore, exercise challenge tests have been used as a safe method to show enhanced bronchial responsiveness. The airway narrowing is thought to be triggered by the respiratory heat $\operatorname{loss}^{6}$ or water $\operatorname{loss}^{7}$ or a combination of the two factors ${ }^{8}$ accompanying the increased ventilation.

By contrast with several studies on short term effects of air pollution on baseline lung function, few have studied effects on bronchial responsiveness among children with asthma. In a study conducted in Mexico City by Castellijos et al an increase in hourly ambient air ozone $\left(\mathrm{O}_{3}\right)$, but not in particles, was found to be associated with decreased lung function after intermittent exercise outdoors. On the other hand, exposure to ambient air pollution in experimental studies has not been associated with increased bronchial responsiveness to cold air ${ }^{10}$ or to methacholine and mite allergen. ${ }^{11}$ Linn et al ${ }^{12}{ }^{13}$ have reported that in exposures in a chamber, which all included intermittent exercise, the simulation of "summer haze" did not result in untoward effects on lung function compared with clean air.

To our knowledge, there are no previous studies on the effects of ambient air pollution on bronchial responsiveness among children during the cold of winter. As northern countries such as Finland have winters that are cold and relatively long, it has been hypothesised that the cold ambient air might enhance the susceptibility of adults and children with asthma

\section{Main message}

- At low concentrations particles derived from combustion affected baseline lung function rather than bronchial responsiveness among children with chronic respiratory symptoms.

\section{Policy implications}

- Efforts to decrease concentrations of ambient air pollutants should continue as harmful health effects are found even at low concentrations.

to concomitant irritant pollutants such as inhalable particles of aerodynamic diameter $<10 \mu \mathrm{m}\left(\mathrm{PM}_{10}\right)$ and nitrogen dioxide $\left(\mathrm{NO}_{2}\right) .{ }^{14}$ On the other hand, daily variations in ambient air particulate pollution have been shown to be associated with declines in lung function in Finnish children. ${ }^{4}$ Therefore, we hypothesised that daily variations in ambient air pollution during the cold in winter would increase exercise induced bronchial responsiveness among children with chronic respiratory symptoms.

\section{SUBJECTS AND METHODS}

The present study was conducted in Kuopio, a town of 85000 inhabitants in eastern Finland, within the framework of the

Abbreviations: $\mathrm{BS}$, black smoke; $\mathrm{O}_{3}$, ozone; $\mathrm{PM}_{10}$, particulate matter of aerodynamic diameter $<10 \mu \mathrm{m}$; PEACE, pollution effects on asthmatic children in Europe; FVC, forced vital capacity; $F_{1}$, forced expiratory volume in 1 second; MMEF, mid-maximal expiratory flow; AEFV, area under the expiratory flow-volume curve; PNC, particle number concentrations; OECD, Organisation for Economic Cooperation 
European collaborative project pollution effects on asthmatic children in Europe (PEACE). ${ }^{15}$

\section{Subjects}

A total of 197 seven to 12 year old primary school children with chronic respiratory symptoms entered the main PEACE study. They were selected from a screening questionnaire on respiratory symptoms completed by parents. The questionnaire was distributed through schools. A child was eligible to enter the study if he or she had ever had asthma diagnosed by a doctor, or in the past 12 months had had wheezing, attacks of shortness of breath with wheezing, or dry nocturnal cough apart from colds. ${ }^{15} 16$ All 33 children, who had agreed to participate in the main PEACE study and were attending either of the two schools in the centre of the town, were asked to participate in the present study. They all agreed, making the final study group 18 boys and 15 girls. One boy did not take part in the exercise challenge tests but he took part in the baseline spirometric measurements. The schools were selected because they were close to an ambient air monitoring site.

The mean age of the children was 9.9 years. Seven children had asthma diagnosed by a doctor, and 18 children had dry nocturnal cough as their only chronic respiratory symptom. A total of four children used daily respiratory medication. Twenty children had at least one positive reaction to skin prick tests. The allergens tested were birch, common alder, mugwort, timothy grass, cat, dog, and house dust mite (Dermatophagoides pteronyssinus). The detailed results from the screening and characterisation phase of the PEACE study have been published. ${ }^{17}$

\section{Study design}

Every alternate school week from February to April 1994, the children took part in an exercise challenge test conducted outdoors at the school yard. Each child participated in a maximum of five tests, which always took place at the same time on the same day of the week. Spirometric lung functions were measured indoors before the exercise, and 3 and 10 minutes after. Before the series of exercise challenge tests outdoors, the children participated once in a similar test indoors to become familiar with the protocol and equipment.

The study protocol was approved by the ethics committee of the University of Kuopio and Kuopio University Hospital. Written consent was obtained from the parents of each child.

\section{Exercise challenge test}

A standardised exercise challenge test was made with a bicycle ergometer (Monark 818E; Ergomedic, Varberg, Sweden) that was placed outdoors in the school yard. The test lasted for 8 minutes, and it was made according to the recommendations of the European Respiratory Society. ${ }^{18}$ During the test, the nose was clipped, and the heart rate was monitored with a Sport Tester heart rate meter (Polar Electro; Kempele, Finland). The target workload was $75 \%-80 \%$ of the maximum heart rate calculated from the equation 205-(1/2 age)-that is, 160 beats/min for a 10 year old child. For the first minute, the workload was set to $60 \%$ of the target load. This was increased to $75 \%$ in the 2 nd minute, $90 \%$ in the 3 rd minute, and $100 \%$ in the 4 th minute, and then held at this level for the remaining 4 minutes.

\section{Lung function tests}

Spirometric flow-volume curves were recorded with a portable computerised spirometer with a heated pneumotachograph (Medikro 909, Medikro Oy, Kuopio, Finland). Three successful flow-volume curves were recorded before the exercise, and two successful curves were recorded at 3 and 10 minutes after the exercise. The measurements were made according to the recommendations of the European Respiratory Society. ${ }^{19}$ The subjects were seated and used a noseclip. At each time point, the largest values of forced vital capacity (FVC), forced expiratory volume in 1 second $\left(\mathrm{FEV}_{1}\right)$, midmaximal expiratory flow (MMEF), and area under the expiratory flow-volume curve (AEFV) were selected from the accepted recordings for the analyses. All spirometric results were corrected to body temperature, atmospheric pressure, and saturation with water vapour.

All lung function tests were made at schools between 0900 and 1500. The children were advised to avoid the use of any inhalable anti-inflammatory medication and short acting bronchodilators for 6 hours, and salmeterol for 8 hours, before the test, and any other medication for 1 hour before the test. The medication used was asked for before every test, and one child was not able to follow the advice before one test and another child before three tests.

\section{Air quality measurements}

During the study period, daily concentrations of ambient air pollutants were monitored at a fixed monitoring site in the centre of Kuopio. The monitoring site was at least 50 meters from any of the surrounding streets as described earlier. ${ }^{20} 21$ Both schools were located within $1 \mathrm{~km}$ of the monitoring site along the same street. There were no major point sources of air pollution close to the schools.

The $\mathrm{PM}_{10}$ measurements were collected with a single stage Harvard impactor (Air Diagnostics and Engineering, Naples, Maine, USA). Black smoke (BS) was sampled according to the OECD protocol. ${ }^{22}$ Particle number concentrations (PNCs) in 12 consecutive size classes ranging from $10 \mathrm{~nm}$ to $10.0 \mu \mathrm{m}$ were measured with an aerosol spectrometer. This has been shown to be highly comparable with other aerosol spectrometers in measuring the number of particles in the submicrometer range, but it may overestimate the number of larger particles. ${ }^{23}{ }^{24}$ For the statistical analyses, two adjacent size classes were combined to form six size classes: 0.01-0.032 $\mu \mathrm{m}$, $0.032-0.1 \mu \mathrm{m}, 0.1-0.32 \mu \mathrm{m}, 0.32-1.0 \mu \mathrm{m}, 1.0-3.2 \mu \mathrm{m}$, and $3.2-10 \mu \mathrm{m}$. The classes are referred to as PNC 0.01-0.03 to PNC $3.2-10$, respectively. The PNC measurements were available only until 9 April 1994. Gaseous pollutants were measured with continuously recording monitors: $\mathrm{NO}_{2}$ with chemiluminescence (Monitor Labs 8840) and $\mathrm{SO}_{2}$ with UV fluorescence (Monitor Labs 8850), and CO with a non-dispersive infrared monitor (Thermo Environmental 48). Filters for 24 hour measurements of $\mathrm{PM}_{10}$ and BS were always changed between 1100 and 1400. Twenty four hour means of the other pollutants were calculated from noon to noon.

Ambient temperature and relative humidity were measured during the exercise tests in the school yard with a Vaisala humidity and temperature indicator (Vaisala HMI 31, Vaisala Oyj, Vantaa, Finland).

\section{Statistical analyses}

Data were analyzed with the statistical package SAS (SAS Institute, Cary, NC, USA). To calculate the change in each spirometric lung function variable, the lower value from the measurements at 3 and 10 minutes after exercise was chosen. Then, the baseline value recorded before exercise was subtracted from this value. The changes in lung function are presented as percentage from the baseline value. For the exposure variables, lag 0 was defined as a 24 hour period from the previous day noon to noon of the day of the lung function measurements. The 4 day mean was calculated as the mean of lag 0 to lag 3 allowing one missing value. Linear regression analyses were conducted with PROC MIXED in SAS. ${ }^{25}$ The dependence of the observations within a child was taken into account in regression modelling. Because of the great variability of lung function measurements between the children, the constant correlation structure was used. In all models, adjustments were made for ambient temperature, relative humidity, and a linear time trend. Possible non-linear 
Table 1 Descriptive statistics of exercise induced changes and baseline concentrations of lung function variables, meteorological variables during the tests, and mean daily concentrations of air pollution during the study period

\begin{tabular}{|c|c|c|c|c|}
\hline & $\mathrm{n}$ & Mean & Range & IQR \\
\hline$\Delta \mathrm{FEV}_{1}(\%)$ & 139 & -2.2 & $-14.0-12.1$ & \\
\hline$\triangle M M E F(\%)$ & 138 & -6.6 & $-48.3-25.1$ & \\
\hline$\triangle \mathrm{AEFV}(\%)$ & 139 & -5.7 & $-24.3-20.1$ & \\
\hline FVCO (I) & 151 & 2.55 & $1.57-3.71$ & \\
\hline $\mathrm{FEV}_{1}($ (I) & 151 & 2.18 & $1.30-3.40$ & \\
\hline MMEF (I/s) & 151 & 2.53 & $1.19-5.27$ & \\
\hline $\operatorname{AEFV}\left(\left.\right|^{2} / \mathrm{s}\right)$ & 151 & 6.8 & $2.19-16.49$ & \\
\hline Test temperature $\left({ }^{\circ} \mathrm{C}\right)$ & 141 & -1.6 & $-24.4-14.0$ & \\
\hline Test $\mathrm{RH}^{*}(\%)$ & 141 & 58.8 & $18.1-88.2$ & \\
\hline$P M_{10}\left(\mu \mathrm{g} / \mathrm{m}^{3}\right)$ & 85 & 25 & $4-158$ & 18 \\
\hline Black smoke $\left(\mu \mathrm{g} / \mathrm{m}^{3}\right)$ & 85 & 13 & $1-57$ & 9 \\
\hline $\mathrm{NO}_{2}\left(\mu \mathrm{g} / \mathrm{m}^{3}\right)$ & 82 & 28 & $5-78$ & 11 \\
\hline $\mathrm{CO}\left(\mathrm{mg} / \mathrm{m}^{3}\right)$ & 82 & 0.6 & $0.1-2.8$ & 0.32 \\
\hline PNC $0.01-0.03 \dagger\left(\mathrm{n} / \mathrm{cm}^{3}\right)$ & 59 & 28829 & $6959-83879$ & 11673 \\
\hline PNC $0.03-0.1 \dagger\left(\mathrm{n} / \mathrm{cm}^{3}\right)$ & 59 & 14991 & $3756-59464$ & 7813 \\
\hline PNC $0.1-0.3 \dagger\left(\mathrm{n} / \mathrm{cm}^{3}\right)$ & 59 & 1986 & $383-7642$ & 702 \\
\hline PNC 0.3-1.0† $\left(\mathrm{n} / \mathrm{cm}^{3}\right)$ & 59 & 115 & $25-287$ & 39 \\
\hline PNC 1.0-3.2† (n/ $\left./ \mathrm{cm}^{3}\right)$ & 59 & 3.5 & $0.9-11.9$ & 1.61 \\
\hline PNC 3.2-10† $\left(\mathrm{n} / \mathrm{cm}^{3}\right)$ & 59 & 0.5 & $0.2-1.6$ & 0.18 \\
\hline
\end{tabular}

* Relative humidity; + Particle number concentration in size ranges of $0.01-0.032 \mu \mathrm{m}, 0.032-0.1 \mu \mathrm{m}, 0.1-0.32 \mu \mathrm{m}, 0.32-1.0 \mu \mathrm{m}$, $1.0-3.2 \mu \mathrm{m}$, and $3.2-10 \mu \mathrm{m}$ respectively.

Interquartile ranges of the lag 0 concentrations of the pollutants (IQR) are presented. Lag 0 is defined as the 24 hour period from the previous day noon to noon of the day of the lung function measurements.

associations for temperature, humidity, and time trend were explored and were not found.

\section{RESULTS}

The total number of tests of baseline lung function was 151 , and a total of 141 exercise tests were completed. The corresponding numbers of tests conducted by 9 April 1994, were 107 and 99, respectively. Each child participated in the 8 minute exercise challenge test on average 4.3 (range 0-5) times, and in the baseline lung function measurements 4.6 $(2-5,94 \%$ of the children at least 4$)$ times. The mean (SD) workload at the end of the exercise was 60 (19.5) W and the mean (SD) heart rate of the children was $166(6.8)$ beats/min.

On average, the changes in lung function induced by exercise were small (table 1). Fifteen children had at least one decrease of $5 \%$ or more in FEV after the exercise.

During the study period, the numbers of ultrafine particles were high compared with larger cities, ${ }^{25}$ whereas the mass of particles was generally low (table 1, fig 1). In April, however, there were high 24 hour concentrations of $\mathrm{PM}_{10}$ due to resuspended dust. The $\mathrm{SO}_{2}$ concentration stayed below $12 \mu \mathrm{g} / \mathrm{m}^{3}$ on all but 6 days when it was $14-32 \mu \mathrm{g} / \mathrm{m}^{3}$. The median $\mathrm{SO}_{2}$ concentration was $3.3 \mu \mathrm{g} / \mathrm{m}^{3}$. All measures of air pollution correlated significantly with each other (table 2 ).

None of the air pollution variables had any significant association with the exercise induced impairment in lung function (table 3). The associations of PNC 0.03-0.1, PNC 0.10.3 , PNC $0.3-1.0$, PNC 1.0-3.2, and PNC 3.2-10 with the exercise induced changes in lung function (data not shown) were similar to those of PNC 0.01-0.03 shown in table 3. After adjusting for time trend, the variation in temperature and relative humidity was not significantly associated with impairment in lung function induced by exercise.

The baseline spirometric lung functions decreased with increasing concentrations of air pollution (table 4). The reductions in FVC and $\mathrm{FEV}_{1}$ were $0.5 \%$ and $0.6 \%$, respectively, for each $10 \mu \mathrm{g} / \mathrm{m}^{3}$ increase in BS (lag 2). The effect estimate of BS (lag 2) on baseline $\mathrm{FEV}_{1}$, without adjustments for time trend, temperature, and relative humidity, for an interquartile increase in pollutant, was $-8.95(\mathrm{p}=0.0792)$. The corresponding adjusted estimate was $-11.9(\mathrm{p}=0.0294)$. The particle number concentrations in different size classes were also significantly associated with declines in spirometric lung functions (table 5).

As the PNC measurements continued only until 9 April, the analyses on the associations of $\mathrm{BS}$ and $\mathrm{PM}_{10}$ with baseline
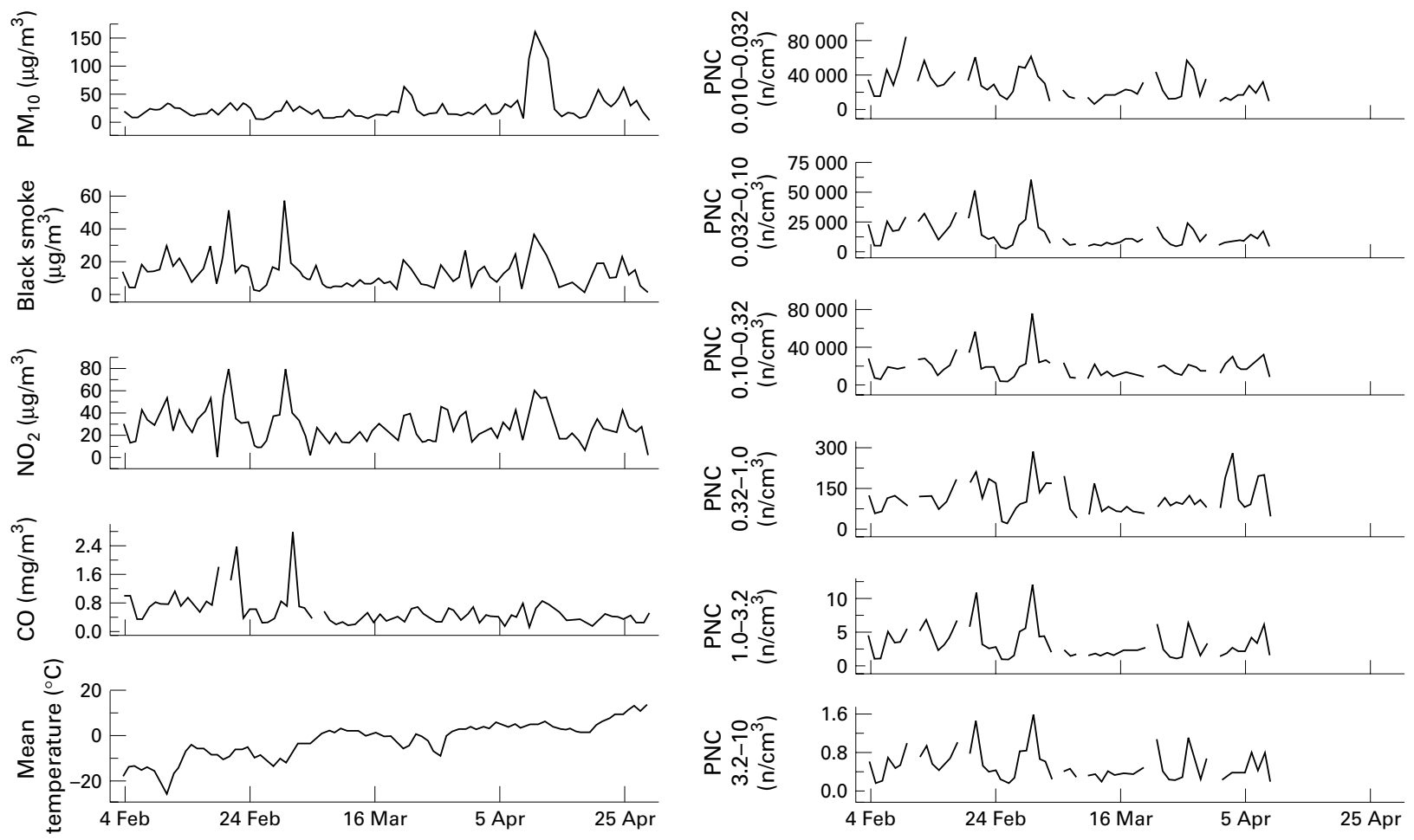

Figure 1 Daily mean concentrations of $\mathrm{PM}_{10}, \mathrm{BS}, \mathrm{NO}_{2}, \mathrm{CO}$, ambient temperature, and PNCs in six size classes. 
Table 2 Spearman's correlations between average daily concentrations of air pollutants and temperature

\begin{tabular}{|c|c|c|c|c|c|c|c|c|c|c|c|}
\hline & $\mathrm{PM}_{10}$ & $\begin{array}{l}\text { Black } \\
\text { Smoke }\end{array}$ & $\begin{array}{l}\text { PNC } \\
0.01-0.03\end{array}$ & $\begin{array}{l}\text { PNC } \\
0.03-0.1\end{array}$ & $\begin{array}{l}\text { PNC } \\
0.1-0.3\end{array}$ & $\begin{array}{l}\text { PNC } \\
0.3-1.0\end{array}$ & $\begin{array}{l}\text { PNC } \\
1.0-3.2\end{array}$ & $\begin{array}{l}\text { PNC } \\
3.2-10\end{array}$ & $\mathrm{NO}_{2}$ & $\mathrm{CO}$ & ${ }^{\circ} \mathrm{C}$ \\
\hline$P M_{10}$ & 1.0 & 0.80 & 0.56 & 0.70 & 0.82 & 0.80 & 0.75 & 0.66 & 0.64 & 0.52 & 0.12 \\
\hline Black smoke & & 1.0 & 0.74 & 0.87 & 0.87 & 0.81 & 0.88 & 0.80 & 0.88 & 0.80 & -0.12 \\
\hline PNC 0.01-0.03 & & & 1.0 & 0.92 & 0.53 & 0.37 & 0.89 & 0.90 & 0.88 & 0.81 & -0.54 \\
\hline PNC 0.03-0.1 & & & & 1.0 & 0.75 & 0.58 & 0.98 & 0.94 & 0.92 & 0.87 & -0.43 \\
\hline PNC $0.1-0.3$ & & & & & 1.0 & 0.92 & 0.79 & 0.68 & 0.69 & 0.71 & -0.12 \\
\hline PNC $0.3-1.0$ & & & & & & 1.0 & 0.61 & 0.50 & 0.56 & 0.60 & -0.09 \\
\hline PNC 1.0-3.2 & & & & & & & 1.0 & 0.95 & 0.91 & 0.84 & -0.34 \\
\hline PNC 3.2-10 & & & & & & & & 1.0 & 0.88 & 0.79 & -0.32 \\
\hline $\mathrm{NO}_{2}$ & & & & & & & & & 1.0 & 0.85 & -0.17 \\
\hline $\mathrm{CO}^{2}$ & & & & & & & & & & 1.0 & -0.43 \\
\hline
\end{tabular}

All correlation coefficients, but those of $\mathrm{PM}_{10}$, black smoke, $\mathrm{PNC} 0.1-0.3, \mathrm{PNC} 0.3-1.0$, and $\mathrm{NO}_{2}$ with temperature, are significant at the p<0.05 level.

Table 3 Adjusted associations between 24 hour concentrations of air pollutants and exercise induced changes in lung functions

\begin{tabular}{|c|c|c|c|}
\hline Pollutant & $\Delta \mathrm{FEV}_{1}(\%)$ & $\triangle M M E F(\%)$ & $\triangle \mathrm{AEFV}(\%)$ \\
\hline \multicolumn{4}{|l|}{$\mathrm{PM}_{10}:$} \\
\hline Lag0 & $0.049(0.238)$ & $0.421(0.658)$ & $0.349(0.439)$ \\
\hline $\operatorname{Lag} 1$ & $0.051(0.172)$ & $0.316(0.475)$ & $0.327(0.316)$ \\
\hline Lag2 & $-0.004(0.165)$ & $-0.029(0.458)$ & $0.313(0.304)$ \\
\hline Lag3 & $-0.031(0.200)$ & $-0.393(0.558)$ & $0.232(0.268)$ \\
\hline 4 Day mean & $0.019(0.215)$ & $0.087(0.597)$ & 0.400 (0.396) \\
\hline \multicolumn{4}{|l|}{ Black smoke: } \\
\hline & $-0.082(0.474)$ & 0.704 (1.31) & $0.544(0.876)$ \\
\hline $\operatorname{Lag} 1$ & & $0.696(0.742)$ & \\
\hline Lag & $0.070(0.266)$ & $0.256(0.736)$ & $4(0.485)$ \\
\hline Lag & 4) & -0 & 0.1 \\
\hline 4 Day mean & $0.003(0.420)$ & & $1.06(0.772)$ \\
\hline \multicolumn{4}{|l|}{ PNC 0.01-0.03: } \\
\hline Lag0 & (0.702) & & $5(1.27)$ \\
\hline $\operatorname{Lag} 1$ & & & \\
\hline Lag2 & & & $7(0.668)$ \\
\hline Lag3 & $0.116(0.436)$ & $(1.17)$ & $2(0.742)$ \\
\hline 4 Day mean & & & 1.72 \\
\hline \multicolumn{4}{|l|}{$\mathrm{NO}_{2}$ : } \\
\hline Lag0 & & $0.880(0.957)$ & 0.688 (0.639) \\
\hline $\operatorname{Lag} 1$ & $0.102(0.227)$ & 2 (0.627) & $0(0.416)$ \\
\hline Lag2 & $0.012(0.228)$ & $-0.097(0.633)$ & $0.632(0.421)$ \\
\hline Lag3 & $-0.074(0.250)$ & $-0.443(0.689)$ & 0.352 (0.438) \\
\hline 4 Day mean & $0.163(0.381)$ & $(1.05)$ & $1.14(0.665)$ \\
\hline \multicolumn{4}{|l|}{$\mathrm{CO}:$} \\
\hline $\operatorname{Lag} 0$ & 31 (0.647) & 0.442 (1.79) & 0.287 (1.19) \\
\hline $\operatorname{Lag} 1$ & $0.030(0.262)$ & $0.520(0.723)$ & $0.281(0.482)$ \\
\hline Lag2 & $0.087(0.260)$ & 0.313 (0.719) & $0.904(0.474)$ \\
\hline $\operatorname{Lag} 3$ & $-0.091(0.275)$ & $-0.616(0.750)$ & $0.150(0.483)$ \\
\hline 4 Day mean & $0.190(0.599)$ & $0.096(1.64)$ & $1.60(1.05)$ \\
\hline
\end{tabular}

The recordings $(n=141)$ were made between 8 February and 29 April 1994, except for PNC between 8 February and 9 April 1994 $(n=99)$. The regression coefficients (SEs) are expressed for an interquartile increase in the concentration of the pollutant.

$\mathrm{FEV}_{1}$ were conducted also with restriction to the same study period as for PNC. By comparison with the whole study period extending to 29 April, the effect estimates of BS remained essentially unchanged and those of $\mathrm{PM}_{10}$ were similar to those of BS.

As sensitivity analyses, the children were stratified into two groups according to their symptoms reported in the screening questionnaire and the results in the skin prick tests. There was no difference in the effect of BS on baseline FEV, between the groups with asthmatic symptoms (asthma ever diagnosed by a doctor, wheezing or attacks of shortness of breath with wheezing in the past 12 months) and of having a dry nocturnal cough as the sole symptom, or between atopic (at least one positive reaction in the skin prick test) and non-atopic children. Also, the BS data were divided into quartiles to explore the linearity of the association between the concentra- tion of BS and baseline $\mathrm{FEV}_{1}$. This analysis supported the linear relation between these two variables.

\section{DISCUSSION}

This is, to our knowledge, the first study to investigate the effects of daily variations in ambient air pollution on short term changes in bronchial responsiveness of children in cold climates. We found that increased concentrations of pollutants in ambient air were not associated with increased bronchial responsiveness that was assessed by changes in lung function caused by a standardised exercise test outdoors. However, high concentrations of $\mathrm{BS}, \mathrm{PM}_{10}, \mathrm{PNCs}, \mathrm{NO}_{2}$, and $\mathrm{CO}$ were significantly associated with lower levels of baseline lung function in these children. These findings support the view that the effects of pollution on these two end points were truly separate for biological reasons and not because of the few observations.

The spirometric lung function responses to the 8 minute standardised bicycle exercise were overall small in the present study. On average, $\mathrm{FEV}_{1}$ decreased by $2.2 \%$. This is consistent with our previous study, in which the same exercise protocol was used indoors and a 3.5\% mean reduction in FEV 1 was found among children with chronic respiratory symptoms. ${ }^{26}$ That study was conducted during a high birch pollen season in May. Furthermore, Remes $\mathrm{et} \mathrm{l}^{27}$ have conducted tests on free running during summertime among primary school children in Kuopio. They found a mean fall of $4.6 \%$ in $\mathrm{FEV}_{1}$ among children with asthma or wheeze and a mean fall of $3.1 \%$ among children with nocturnal cough only.

We found no consistent association between the changes in concentrations of ambient air pollutant and bronchial responsiveness to outdoor exercise. Previously, in the study of Castillejos et al in Mexico City, increases in hourly ambient air $\mathrm{O}_{3}$, but not in particles, were associated with declines in lung function after 1 hour of intermittent exercise in children with chronic respiratory symptoms. In experimental studies conducted among children with asthma, short term exposures to mixed oxidant gases $\left(\mathrm{NO}_{2}+\mathrm{O}_{3}\right.$, with and without $\left.\mathrm{H}_{2} \mathrm{SO}_{4}\right)$, acid aerosols, $\mathrm{NO}_{2}, \mathrm{SO}_{2}$, or ambient polluted air have not been associated with enhanced bronchial responsiveness to exercise ${ }^{10} 12$ or to allergen and methacholine challenge. ${ }^{11}$ The results of the present study support the view that short term changes in ambient air pollution are not associated with changes in exercise induced bronchial responsiveness among children. However, as the present study was conducted during winter in a location where both $\mathrm{O}_{3}$ and $\mathrm{SO}_{2}$ concentrations were negligible, the results do not account for the possible effects of these pollutants on bronchial responsiveness.

Baseline spirometric lung function of the children decreased with increasing concentrations of air pollution. The most consistent effects were found for $\mathrm{BS}$ and $\mathrm{NO}_{2}$, which originate mainly from combustion processes- that is, traffic in Kuopio-and for the numbers of particles of $0.1-1.0 \mu \mathrm{m}$. 
Table 4 Adjusted associations between 24 hour concntrations of air pollutants and baseline lung functions

\begin{tabular}{|c|c|c|c|c|}
\hline Pollutant & $\mathrm{FVC}(\mathrm{ml})$ & $\mathrm{FEV}_{1}(\mathrm{ml})$ & MMEF $(\mathrm{ml} / \mathrm{s})$ & $\operatorname{AEFV}\left(I^{2} / s\right)$ \\
\hline \multicolumn{5}{|l|}{$\mathrm{PM}_{10}:$} \\
\hline Lago & $-5.04(4.00)$ & $-3.96(4.90)$ & -8.67 (13.7) & $-0.026(0.033)$ \\
\hline $\operatorname{Lag} 1$ & $-4.94(2.93)$ & $-2.48(3.61)$ & $-9.33(10.0)$ & $-0.029(0.024)$ \\
\hline $\operatorname{Lag} 2$ & $-6.50(2.80) *$ & $-4.68(3.47)$ & $-10.5(9.68)$ & $-0.043(0.023)$ \\
\hline Lag3 & $-8.21(3.42)^{*}$ & $-4.74(4.25)$ & $-12.0(11.8)$ & $-0.046(0.028)$ \\
\hline 4 Day mean & $-7.96(3.61)^{*}$ & $-5.06(4.48)$ & $-13.1(12.5)$ & $-0.047(0.030)$ \\
\hline \multicolumn{5}{|l|}{ Black smoke: } \\
\hline Lag0 & $-12.4(7.88)$ & $-9.20(9.67)$ & -24.4 (26.9) & $-0.099(0.064)$ \\
\hline Lag 1 & $-8.80(4.59)$ & $-10.1(5.60)$ & $-26.0(15.6)$ & $-0.082(0.037)$ * \\
\hline Lag2 & $-12.6(4.36) \dagger$ & $-11.9(5.40)^{*}$ & $-20.4(15.2)$ & $-0.093(0.036)$ * \\
\hline $\operatorname{Lag} 3$ & $-14.1(4.94) \dagger$ & $-11.5(6.14)$ & $-33.8(17.0)^{*}$ & $-0.070(0.041)$ \\
\hline 4 Day mean & $-21.1(6.64) \dagger$ & $-19.6(8.25)^{*}$ & $-46.7(23.1) *$ & $-0.151(0.054) \dagger$ \\
\hline \multicolumn{5}{|l|}{$\mathrm{NO}_{2}$ : } \\
\hline Lag0 & $-4.00(5.77)$ & $0.219(7.05)$ & $-11.9(19.6)$ & $-0.051(0.047)$ \\
\hline $\operatorname{Lag} 1$ & $-6.35(3.90)$ & $-6.68(4.77)$ & $-19.0(13.2)$ & $-0.071(0.031)^{*}$ \\
\hline Lag2 & $-10.8(3.69) \dagger$ & $-11.4(4.54)$ * & $-19.1(12.9)$ & $-0.077(0.030)$ * \\
\hline Lag3 & $-12.6(4.40) \dagger$ & $-8.19(5.44)$ & $-22.2(15.0)$ & $-0.048(0.036)$ \\
\hline 4 Day mean & $-17.7(6.57) \dagger$ & $-10.6(8.10)$ & $-23.7(22.5)$ & $-0.086(0.053)$ \\
\hline \multicolumn{5}{|l|}{$\mathrm{CO}:$} \\
\hline Lag0 & 0.064 (10.9) & 19.2 (13.2) & $22.2(36.9)$ & $0.093(0.088)$ \\
\hline Lag 1 & $-4.79(4.51)$ & $-9.04(5.45)$ & $-23.0(15.2)$ & $-0.068(0.036)$ \\
\hline Lag2 & $-9.78(4.24)^{*}$ & $-9.15(5.21)$ & -4.63 (14.7) & $-0.060(0.035)$ \\
\hline $\operatorname{Lag} 3$ & $-13.9(4.70) \dagger$ & $-11.7(5.77)^{*}$ & $-30.9(16.0)$ & $-0.050(0.039)$ \\
\hline 4 Day mean & $-29.4(10.1) \dagger$ & -17.5 (12.5) & -24.9 (34.8) & $-0.076(0.083)$ \\
\hline
\end{tabular}

${ }^{*} p<0.05 ; \dagger p<0.01$.

The recordings $(n=141)$ were between 8 February and 29 April 1994. The regression coefficients (SEs) are expressed for an interquartile increase in the concentration of the pollutant.

Table 5 Adjusted associations between 24 hour concentrations of particle number and baseline lung functions

\begin{tabular}{|c|c|c|c|c|}
\hline Pollutant & FVC (I) & $\mathrm{FEV}_{1}(\mathrm{I})$ & MMEF (l/s) & $\operatorname{AEFV}\left(I^{2} / s\right)$ \\
\hline \multicolumn{5}{|c|}{ PNC 0.01-0.03: } \\
\hline $\operatorname{Lag} 0$ & 12.5 (9.87) & $8.40(12.8)$ & 12.3 (41.4) & $-0.053(0.070)$ \\
\hline Lagl & $7.22(7.06)$ & $-4.43(8.96)$ & $-27.5(28.7)$ & $-0.070(0.050)$ \\
\hline Lag2 & $-1.20(5.01)$ & $-5.51(6.25)$ & $1.53(20.0)$ & $-0.010(0.036)$ \\
\hline Lag3 & $-12.8(7.43)$ & $-15.2(8.70)$ & $-28.1(27.5)$ & $-0.056(0.047)$ \\
\hline 4 Day mean & $0.200(8.08)$ & $-13.2(10.1)$ & -32.5 (32.9) & $-0.084(0.057)$ \\
\hline \multicolumn{5}{|l|}{ PNC 0.03-0.1: } \\
\hline $\operatorname{Lag} 0$ & 16.2 (11.7) & $19.0(15.1)$ & 2.24 (4.92) & $-0.032(0.083)$ \\
\hline $\operatorname{Lag} 1$ & 1.37 (5.25) & $-10.7(6.50)$ & $-36.4(20.9)$ & $-0.083(0.036)$ * \\
\hline $\operatorname{Lag} 2$ & $-4.46(4.29)$ & $-9.27(5.31)$ & $-2.94(17.3)$ & $-0.040(0.031)$ \\
\hline Lag3 & $-12.7(4.93)^{*}$ & $-14.0(5.83)^{*}$ & $-28.0(18.7)$ & $-0.052(0.032)$ \\
\hline 4 Day mean & $-7.46(6.64)$ & $-19.5(8.18)^{*}$ & $-43.4(27.0)$ & $-0.107(0.047)^{*}$ \\
\hline \multicolumn{5}{|l|}{ PNC 0.1-0.3: } \\
\hline $\operatorname{Lag} 0$ & $5.36(9.54)$ & 3.58 (12.3) & $-36.8(39.6)$ & $-0.027(0.068)$ \\
\hline $\operatorname{Lag} 1$ & $-3.23(4.29)$ & $-12.3(5.23)^{*}$ & $-29.4(17.2)$ & $-0.068(0.029)^{*}$ \\
\hline Lag2 & $-6.54(3.83)$ & $-10.9(4.74)^{*}$ & $-6.65(15.7)$ & $-0.054(0.027)^{*}$ \\
\hline $\operatorname{Lag} 3$ & $-9.50(3.79)$ * & $-11.5(4.44)^{*}$ & $-22.5(14.4)$ & $-0.047(0.024)^{*}$ \\
\hline 4 Day mean & $-10.5(5.47)$ & $-20.4(6.70)^{* *}$ & $-40.0(22.5)$ & $-0.104(0.039)$ ** \\
\hline \multicolumn{5}{|l|}{ PNC 0.3-1.0: } \\
\hline $\operatorname{Lag} 0$ & $-3.87(6.26)$ & $-4.35(8.09)$ & -31.0 (25.9) & $-0.024(0.044)$ \\
\hline $\operatorname{Lag} 1$ & $-14.3(6.51)^{*}$ & $-22.9(8.03)^{* *}$ & $-45.8(26.8)$ & $-0.072(0.047)$ \\
\hline Lag2 & $-10.3(6.13)$ & $-22.4(7.32)^{* *}$ & $-26.7(24.9)$ & $-0.120(0.042)^{* *}$ \\
\hline Lag3 & $-5.10(3.73)$ & $-8.07(4.32)$ & $-11.7(13.8)$ & $-0.042(0.023)$ \\
\hline 4 Day mean & $-14.3(6.98)^{*}$ & $-26.5(8.57)^{* *}$ & $-49.9(28.9)$ & $-0.136(0.049)^{* *}$ \\
\hline \multicolumn{5}{|l|}{ PNC 1.0-3.2: } \\
\hline Lag0 & $8.60(9.15)$ & $10.8(11.8)$ & $-10.4(38.3)$ & $-0.034(0.065)$ \\
\hline Lag 1 & $1.05(4.88)$ & $-9.54(6.04)$ & $-35.6(19.4)$ & $-0.075(0.033)^{*}$ \\
\hline Lag2 & $-4.18(4.04)$ & $-7.62(5.03)$ & 0.980 (16.3) & $-0.026(0.029)$ \\
\hline Lag3 & $-13.2(4.98)$ * & $-14.1(5.91)^{*}$ & $-29.0(19.0)$ & $-0.052(0.032)$ \\
\hline 4 Day mean & $-7.80(6.53)$ & $-18.5(8.08)^{*}$ & $-43.3(26.6)$ & $-0.100(0.046)^{*}$ \\
\hline \multicolumn{5}{|l|}{ PNC 3.2-10: } \\
\hline $\operatorname{Lag} 0$ & 2.85 (5.88) & $5.07(7.58)$ & $0.938(24.5)$ & $-0.030(0.041)$ \\
\hline Lag 1 & $0.451(4.35)$ & $-8.30(5.39)$ & $-32.2(17.2)$ & $-0.068(0.030)^{*}$ \\
\hline Lag2 & $-2.59(3.36)$ & $-5.54(4.19)$ & 2.35 (13.5) & $-0.014(0.024)$ \\
\hline Lag3 & $-11.8(4.48)^{*}$ & $-13.4(5.27)^{*}$ & $-28.0(16.9)$ & $-0.051(0.029)$ \\
\hline 4 Day mean & $-6.69(5.71)$ & $-15.9(7.06)^{*}$ & $-36.0(23.2)$ & $-0.088(0.040)^{*}$ \\
\hline
\end{tabular}


However, more fine and coarse particles were also associated with declines in spirometric lung function. When the spring season with episodes of resuspended soil dust causing the highest concentrations of $\mathrm{PM}_{10}$ was not included in the analyses, $\mathrm{PM}_{10}$ also had stronger significant associations with decreased lung function. As in our previous study, ${ }^{22}$ we were not able to measure the size of particles responsible for the observed health effects. This difficulty is most likely due to the involvement of the same sources (traffic) in the emissions of particles in the ultrafine (engine exhausts) and coarse (resuspension by traffic flow) fractions during the winter in Kuopio. This involvement of traffic can also explain the high intercorrelations between the different measures of particulate air pollution. By contrast with our previous study, the number of accumulated particles in the mode $(0.3-1.0 \mu \mathrm{m}$ diameter) was also associated with impaired lung function. Unfortunately, there were no PNC measurements during the highest concentrations of $\mathrm{PM}_{10}$ in April, and thus we were not able to separate the effects of ultrafine and coarse particles more precisely.

It is noteworthy that the significant changes in lung function were found not only in FEV, and FVC, but also in AEFV. The AEFV has been shown to be at least as good a lung function variable as $\mathrm{FEV}_{1}$ in measuring bronchoconstriction in methacholine provocation tests in normal subjects. ${ }^{28}$ Our results support the view of the usefulness of this lung function variable to detect small changes in lung function. In the present data, there were fewer significant associations between indices of ambient air particles and MMEF than with $\mathrm{FEV}_{1}$, which may be due to the larger variability of MMEF in children. $^{29}$

The present results on the impairment of baseline lung functions agree with the previous studies on the effects of particulate air pollution on lung function in children..$^{1-3}$ They are also supported by our previous study, ${ }^{4}$ in which PEF decreased by $0.2 \%-0.3 \%$ for a $10 \mu \mathrm{g} / \mathrm{m}^{3}$ increase in BS (lag 2 ) compared with the corresponding decrease of $0.6 \%$ in $\mathrm{FEV}_{1}$ in the present study.

In conclusion, daily variations in ambient air pollution during the cold of winter were not associated with enhanced bronchial responsiveness measured in an exercise challenge test among children with chronic respiratory symptoms. However, high concentrations of $\mathrm{BS}, \mathrm{PM}_{10}$, particle numbers, $\mathrm{NO}_{2}$, and $\mathrm{CO}$ were consistently associated with an impairment of lung function before exercise. Thus, particles derived from combustion affected baseline lung function rather than bronchial responsiveness in these children.

\section{ACKNOWLEDGEMENTS}

This work was supported by a grant from the Academy of Finland, Kerttu and Kalle Viik Foundation, US EPA grant No R825295-01-0.

\section{Authors' affiliations}

K L Timonen, J Pekkanen, P Tiittanen, Unit of Environmental Epidemiology, National Public Health Institute, Kuopio, Finland R O Salonen Laboratory of Toxicology

\section{REFERENCES}

1 Dockery DW, Pope CA III. Acute respiratory effects of particulate air pollution. Annu Rev Public Health 1994;15:107-32.

2 Hoek G, Brunekreef B. Acute effects of a winter air pollution episode on pulmonary function and respiratory symptoms of children. Arch Environ Health 1993;49:328-35.

3 Scarlett JF, Abbott KJ, PeacockJL, et al. Acute effects of summer air pollution on respiratory function in primary school children in southern England. Thorax 1996;51:1109-14.
4 Timonen KL, Pekkanen J. Air pollution and respiratory health among children with asthmatic or cough symptoms. Am J Respir Crit Care Med 1997; 156:546-52.

5 Vedal S, Petkau J, White R, et al. Acute effects of ambient inhalable particles in asthmatic and non-asthmatic children. Am J Respir Crit Care Med 1998; 157:1034-43.

6 McFadden ER Jr. Respiratory heat and water exchange: physiological and clinical implications. J Appl Physiol 1983;54:331-6.

7 Anderson SD. Is there a unifying hypothesis for exercise-induced asthma? J Allergy Clin Immunol 1984;73:660-5

8 Eschenbacher WL, Sheppard D. Respiratory heat loss is not the sole stimulus for bronchoconstriction induced by isocapnic hyperpnea with dry air. Am J Respir Dis 1985:131:894-901.

9 Castellijos M, Gold DR, Damakosh Al, et al. Acute effects of ozone on the pulmonary function of exercising schoolchildren from Mexico City. Am J Respir Crit Care Med 1995;152:1501-7.

10 Avol EL, Linn WS, Peng R-C, et al. Experimental exposures of young asthmatic volunteers to $0.3 \mathrm{ppm}$ nitrogen dioxide and to ambient air pollution. Toxicol Ind Health 1989;5:1025-34.

11 Huang J-L, Wang S-Y, Hsieh K-H. Effect of short-term exposure to low levels of $\mathrm{SO}_{2}$ and $\mathrm{NO}_{x}$ on pulmonary function and methacholine and allergen bronchial sensitivities in asthmatic children. Arch Environ Health 1991;46:296-9.

12 Linn WS, Anderson KR, Shamoo DA, et al. Controlled exposures of young asthmatics to mixed oxidant gases and acid aerosol. Am J Respir Crit Care Med 1995; 152:885-91.

13 Linn WS, Gong H Jr, Shamoo DA, et al. Chamber exposures of children to mixed ozone, sulfur dioxide, and sulfuric acid. Arch Environ Health 1997:52:179-87

14 Salonen RO. Urban air quality and health in Finland. Finnish Air Pollut Prevent News 1995;19:21-4.

15 Roemer W, Hoek G, Brunekreef B, et al. Effects of short-term changes in urban air pollution on the respiratory health of children with chronic respiratory symptoms: the PEACE project: [introduction]. Eur Respir Rev 1998;8:4-11.

16 Timonen KL, Pekkanen J, Salonen RO, et al. Air pollution and respiratory health of children: the PEACE panel study in Kuopio, Finland. Eur Respir Rev 1998:8:27-35.

17 Timonen KL, Pekkanen J, Korppi M, et al. Prevalence and characteristics of children with chronic respiratory symptoms in eastern Finland. Eur Respir J 1995:8:1 155-60.

18 Sterk PJ, Fabbri LM, Quanjer PhH, et al. Airway responsiveness: standardized challenge testing with pharmacological, physical and sensitizing stimuli in adults. Report of the Working Party on Standardization of Lung Function Tests, European Community for Stee and Coal, Official Statement of the European Respiratory Society. Eur Respir J 1993;6(suppl 16):53-83.

19 Quanjer PhH, Tammeling GJ, Cotes JE, et al. Lung volumes and forced ventilatory flows. Report of the Working Party on Standardization of Lung Function Tests, European Community for Coal and Steel, Official Statement of the European Respiratory Society. Eur Respir J 1993;6/supp 16):5-40

20 Reponen A, Ruuskanen J, Mirme A, et al. Comparison of five methods for measuring particulate matter concentrations in cold winter climate.Atmospheric Environment 1996;30:3873-9.

21 Pekkanen J, Timonen KL, Ruuskanen J, et al. Effects of ultra-fine and fine particles in urban air on peak expiratory flow among children with asthmatic symptoms. Environ Res 1997;74:24-33.

22 OECD. Methods of measuring air pollution. Report of the Working Party on Methods of Measuring Air Pollution and Survey Techniques. Paris: OECD, 1964

23 Tuch T, Mirme A, Tamm E, et al. Comparison of two particle size spectrometers for ambient aerosol measurements in environmenta epidemiology. Atmospheric Environment 2000;34:139-49.

24 Khlystov A, Kos GPA, ten Brink HM, et al. Intercomparison using laboratory-generated aerosols. Atmospheric Environment 2001;35:2045-51

25 Littell RC, Milliken GA, Stroup WW, et al. SAS system for mixed models, Cary, NC: SAS Institute, 1996

26 Timonen KL, Randell JT, Salonen RO, et al. Short-term variations in oscillatory and spirometric lung function parameters among school children. Eur Respir J 1997; 10:82-7.

27 Remes S, Korppi M, Remes K, et al. Exercise-induced asthma in the Kuopio area, Eastern Finland. In: Carlsen K-H, Ibsen TB. Exercise-Induced asthma and sports in asthma. Copenhagen: Munksgaard, 1999:42-4.

28 Seppälä O. Reproducibility of methacholine induced bronchoconstriction in healthy subjects: the use of area under the exporatory flow-volume curve to express results. Respir Med 1990;84:387-94.

29 Timonen KL, Randell JT, Salonen RO, et al. Short-term variations in oscillatory and spirometric lung function indices among school children. Eur Respir J 1997;10:82-7. 